\title{
Bilgi Çağında Yükseköğretim Muhasebe Eğitiminde Karşılaşılan Sorunlar ve Öneriler
}

\author{
Gencay KARAKAYA ${ }^{1}$
}

$\ddot{O} z$

Dijitalleşme, sayısallaşma, yapay zekâ, makine öğrenmesi gibi kavramların konuşulduğu günümüz bilgi çağının, eğitim öğretim alanındaki en temel sorunlara henüz çare olamadığı açıkça görülmektedir. Özellikle yükseköğretimde ana bilim dalları düzeyinde oluşturulan ve katma değer oluşturması beklenen müfredatlar, programlar ve ders içerikleri bilgi çağının gerisinde seyretmektedir. Öğrencilere analitik düşünme, muhakeme, sorunu tespit etme ve çözüm bulma gibi temel kazanımların verilmesi hususu halen ihmal edilmektedir. Bu yönüyle üniversitelerin etkin kaynak yönetimleri de sekteye uğramaktadır. Bu nedenle bilgi çağının sunduğu yenilikler ve firsatlar geri planda kalmakta, yükseköğretim seviyesindeki eğitim öğretim, potansiyelden giderek uzaklaşarak vasat altı bir çizgide devam etmektedir. Bu çalışmada, muhasebe eğitimi kapsamında, katma değer oluşturacak bir eğitim öğretim modeli oluşturamama sorunu detaylı şekilde incelenmiştir. Bu bağlamda çalışma kapsamında kavramsal bir çerçeve ile birlikte çok kriterli bir analize de yer verilmiştir.

Anabtar Kelimeler: Bilgi Çağı, Muhasebe, Muhasebe Eğitimi, Yükseköğretim

\section{Problems and Recommendations of Higher Accounting Education in the Information}

Age

\begin{abstract}
It is clear that today's information age, where concepts such as digitalization, digitization, artificial intelligence, machine learning are discussed, has not yet been able to address the most fundamental problems in the field of education and training. The curriculum, programs and course contents that are created at the level of major disciplines especially in higher education and expected to create added value are behind the information age. It is still neglected to give students basic gains such as analytical thinking, reasoning, problem identification and finding solutions. In this respect, effective resource management of universities is also interrupted. Therefore, the innovations and opportunities offered by the information age remain in the background, and education at higher level continues in a subpar line by increasingly moving away from the potential. The aim of this study is to examine in detail the problem of not being able to create an educational model that will provide added value within the scope of accounting education. In this context, with a conceptual framework, a multi-criteria analysis will be included.
\end{abstract}

Key Words: Information Age, Accounting, Accounting Education, Higher Education

Atıf İçin / Please Cite As:

Karakaya, G. (2020). Bilgi çağında yükseköğretim muhasebe eğitiminde karşılaşılan sorunlar ve öneriler. Manas Sosyal Araștirmalar Dergisi, 9(2), 1218-1226.

Geliş Tarihi / Received Date: 08.01.2020

Kabul Tarihi / Accepted Date: 23.03.2020 


\section{Giriş}

Yükseköğretim eğitim politikalarının temel misyonu; analitik düşünebilen, teknoloji kullanım kapasitesi yüksek, kalifiye mezunların olmasıdır. Ülke olarak etkin ve verimli bir istihdam modelinin işletilebilmesinin temel girdisi yine bu mezunlar olacaktır. Fakat yükseköğretim mezunlarının dahi isssizlik oranlarının yüzde 12-13 bantlarına eriştiği bu dönemde, klasik eğitim öğretim modellerinin artık ihtiyac1 karşılayamadığ1 görülmektedir.

Özellikle katma değer oluşturacak mal ve hizmet üretiminin temel aktörü olan yükseköğretim mezunlarının yaşadığı bu sorun, (teknik personellerin bir kısmı istisna olmak üzere) düşük mezuniyet derecelerinde daha yoğun görülmektedir. Bilgi çağının temel yükseköğretim aktörlerini hazırlıksız yakaladığı bu dönemlerde, ilgili kalite ve katma değer sorunsalı giderek derinleşmekte ve önlenmesi görece daha zor hale gelmektedir.

Özellikle mezuniyet akabinde belirli seviyede meslek donanımı edinmiş olması beklenen gruplardan olan muhasebe mesleği, bu katma değer oluşturma zincirinde önemli bir rol oynamaktadır. İsgücü piyasasına baktığımızda, mesleki eğitim almamış kişilerin piyasada yetiştirilmesinin oldukça zor olduğu net olarak görülmektedir. Sadece genel lise eğitimi almış çalışanlar ise verimliliği arzu edilen seviyeye çekmek konusunda yetersiz kalmaktadır (Küçükgöksel ve Akpınar, 2016, s. 3).

Muhasebe biliminin genişleyen çerçevesi ve buna bağlı olarak belirli bir teorisinin de yerleșmiş olması itibariyle üzerinde ciddi düşünülmesi gereken bir hal almıştır. Yükseköğretim muhasebe eğitimleri dikkate alındığında, her bir eğitim öğretim basamağında yaşanılan sorunlar ve beklentiler artmakta, reel sektör beklentileri değişmekte ve bunu karşılayacak donanımlı mezunların artması hayati bir önem arz etmektedir. Söz konusu çalş̧ma kapsamında da yükseköğretim muhasebe eğitiminin temel sorunları ve nedenleri araştırılacak ve çeşitli öneriler sunulmaya çalışılacaktır.

Araştırma örneklemi; söz konusu eğitim ve öğretim sürecinin temel aktörleri olan muhasebe öğretim elemanlarıdır. Araştırma kapsamında hem nitel hem de nicel yöntemlere başvurulmuştur. Bu bağlamda nicel araştırma yöntemlerinden olan AHP Modeli (Analytic Hierarchy Process - Analitik Hiyerarşi Modeli) kullanılmıştır. Nitel yöntemlerden derinlemesine mülakat yöntemi ile muhasebe eğitimi kapsamında temel sorunlar ve değerlendirme kriterleri tespit edilmiş ve modele dâhil edilmiştir. Elde edilen sorunlara ilişkin öncelikler tespit edilmiş ve bu sorunların çözümü için farklı öneriler sunulmuştur.

\section{Bilgi Çağı ve Yükseköğretim Açısından Sonuçları}

Canlı ve dinamik bir organizasyon olarak üniversiteler, sırasıyla bilginin ve bilimin fiziki hamiliğini üstlenen kurumlardır. Yani kurumsal manada yükseköğretimin başladığ1 ve sürdürüldüğü bu alanlar, mensuplarına sadece eğitim ve öğretim vermekle yetinmeyip, sosyal ve beşeri yönlerinin güçlenmesine de olanak tanırlar. Tamda bu yüzden "canlı ve dinamik" sıfatları ile ifade edilirler.

Giderek değişen ve gelişen teknolojik ve bilimsel gelişmeler, üniversitelerin de bu gelişim ve değişimlere ayak uydurmasını elzem kılmıştır. Bu noktada sürecin iki temel girdisi olan öğretim elemanları ve öğrencilerin karşılıklı etkileşimleri ve birbirlerini beslemeleri, sürecin hatmine ulaşıldığında kaliteli sonuçlar çıkabileceği yönünde kuvvetli ipuçları vermektedir. Teorik ve pratik bilimin temel oluşum kaynaklarından ihtiyaçlar ve meraklar, bu sistemi ve gelişimini sembolize eden iki temel kavramdır. Bu sistemi birde dışarıdan besleyen yönetim araçları ve kanalları mevcuttur. Bunlar eğitim öğretim süreçlerinin özünde yer almamakla birlikte, yerleşik yükseköğretim ekosisteminde ki önemli aktörlerdir. Etkin ve verimli bir üniversite yönetimi, öğretim elemanları ve öğrenciler açısından daha az problem ve dolayısıyla daha fazla kalite demektir.

Toplumun değişim ve dönüşümünde yükseköğretim kurumlarının çok büyük katkıları vardır. Özellikle üniversite eğitimini tamamlayan kişilerin, yaşadığı sosyal ya da profesyonel alanlara da etki edecek olan davranışları, ifadeleri, söylemleri bu değişim ve dönüşümün girdilerinden olacaktır. Bu nedenle yükseköğretim kapsamında verilecek bilim ahlakı, bilim felsefesi, sosyal ve beşeri donanımların tamamı, gün sonunda toplumun şekillenmesinde önemli rol oynayacaktır. Öğretim elemanı ve öğrenci arasında ki formel ilişkinin temel araçları olan; müfredatlar, ders programları, ders içerikleri, ders işleme yöntemleri vb. sair tüm konular üzerinde titizlikle durulmalı, icrası ve intacı noktasında azami özen gösterilmelidir.

Yaşadığımız dönemin yükseköğretim evreninde ki temel sorunlarından birisi esasında erişimi ve sayısı sınırsız olan kaynaklara olan rağbetin vasat altı seviyelerde olmasıdır. Özellikle uluslararası birikimlere erişimin hiç olmadığı kadar kolay olduğu bu dönemlerde, maalesef bu konuda ki talep ve istekler gerek 
öğretim elemanları gerekse de öğrenciler tarafında çok düşük seviyelerdedir. Bilgiye erişim maliyetlerinin giderek azalması, çok geniş yelpazede bir kaynak zenginliği maalesef Türkiye özelinde etkin ve verimli bir dışsallık oluşturma noktasında yeteri kadar dikkate alınmamaktadır.

Bilgi çağının sunmuş olduğu bunca firsat ve potansiyel, Türkiye'de yükseköğretim seviyesinde belki de 25 yıllık geleneksel eğitim öğretim modelleri ile sunulmaya çalışılan teorik ve pratik bilgiler sürdürülerek baskılanmaya ve göz ardı edilmeye çalışılmaktadır. Tam da bu noktada, Türkiye'de ki merkezi bilim kurumları ve üniversite yönetimlerinin, bu coğrafyada bilimin varoluş çizgisini değiştirecek dönüşümlere ne tür stratejilerle katkıda bulunabilecekleri sorusu sorulabilir (Kara, 2019, s. 12).

Yükseköğretimin bilişsel ve katma değerli çıktılar sağlayabilmesi açısından yetkili kılınmış tüm kişi ve kurumların hususen üzerinde düşünmeleri gereken asıl soru da budur. Çünkü yükseköğretim rekabetinin en katı ve acımasız manevralarını gördüğümüz bu çağ; bilginin, bilimin, kalitenin ve katma değerin en çok konuşulup en çok irdelendiği çağdır. Dünya yükseköğretim modellerinin dünü ve bugünü irdelendiğinde, cari durumumuz ile ilgili tespitlerimiz esasında bizim çıkış noktamızı belirleyecek olan temel verilerdir.

Bununla birlikte yükseköğretim ekosisteminin giderek genişleyen çerçevesi iyi tahlil edilmeli ve ihtiyaçların bu ekosistem özelinde sorunlara çözüm bulacak tarzda modellenmesi gerekmektedir. Başlı başına bir sitem ağını ifade eden yükseköğretim kurumlarının yeniden etkin kılınması için; ekosistem içerisinde yer alan iş dünyasının, bürokrasinin, sivil toplumun ve ilgili tüm paydaşların olası etkileri ve katkıları değerlendirilmelidir. İhtiyaçlara uygun olmayan hiçbir mal/hizmet rağbet görmeyecek ve uzun vadede işlerliğini sürdüremeyecektir. Yükseköğretimin bu noktada ihtiyaca uygun politika ve yöntemleri kullanmak suretiyle ilgililere sunacağı, bilim ve bilgi üretimi noktasında asgari donanımı olan, teknoloji kullanım kapasitesi yüksek, kalifiye mezunlar ile "salt meslek edindirmekle görevli" birimler olmaktan kurtulması gerekmektedir. Temel amacı meslek- edindirmekle sınırlı olanlar hariç, üniversitelerde, bilimüretimi, öncelikli gündem maddeleri arasında yer almalı, diğer kurumlarla ilişkiler bu öncelik korunarak geliştirilmelidir (Kara, 2019, s. 15).

\section{Bilgi Çağ́1 ve Muhasebe Eğitimi}

İçinde bulunduğumuz çağın temel dinamiği bilgi ve bilim endeksli ilerlemektedir. Bu sayede katma değer ve kaliteli süreçlerin tamamı için temel girdi olarak yine bu iki kavram kullanılmaktadır. Bunun dışında yer alan tüm girdiler tali unsurlar olarak karşımıza çıkmaktadır. Tabi ki bu durum Türkiye için halen ulaşılmaya çalışılan bir hedef durumundadır. Klasik eğitim-öğretim metotları, işletme yönetim modelleri vb. geleneksel çizgide ilerleyen ana akım (başat) konular, hala çağın gereksinimleri ve ihtiyaçları ile örtüşmemektedir.

Bu noktadan hareketle, yükseköğretim muhasebe eğitim ve öğretim teorisinin aktarıldığı akademik mecralarda ve uygulanacağı pratik alanlarda bilgi çağının asgari şartlarının yerine getirilmesi gerekmektedir. Çalışmanın temel hareket noktası da bu sorunun çözümüne ilişkin yapılması gereken aksiyonlarla ilgilidir. Muhasebe meslek icracılarının karmaşık muhasebe sorunlarının üstesinden gelip, farklı kişi ve grupların ihtiyaçlarını karşılayabilecek nitelikteki malî tablolanı, mevcut hukukî düzenlemeler ile muhasebe standartlarında belirtilen kurallar çerçevesinde hazırlayabilmeleri, onların eğitim kurumlarında veya uygulama anında edindikleri muhasebe eğitim düzeyleri ile yakından ilgilidir (Çürük ve Doğan, 2001, s. 25).

Muhasebe eğitiminin temel amacı; mezunların iş hayatına başladığında, işletme kararlarına faydalı verilerin tespit edilmesi, sınanması, kaydedilmesi, doğruluğunun incelenmesi, açıklamalı raporlanması ve bu raporlardan elde edilen sonuçların karar almada kullanılması konusunda bilgilendirilmesi ve bu bilgilerin kullanılması için bireyin yeteneğinin geliştirilmesidir (Gökçen, 1998, s. 43). Muhasebe eğitimi, muhasebe mesleğinin işlevsel gereksinimlerine odaklanmış mesleki bilgi temelli olsa da özünde kişisel nitelikler ve etik değerlerle harmanlanmış olmalıdır (Alkan, 2015, s. 138). Tüm bunlarla birlikte; muhasebe eğitiminin tek amacı, mezunların kalifiye bir meslek mensubu haline getirmek değil aynı zamanda onları öğrenebilme becerisini ve inovasyon becerisini kazandırmaktır. Bu nedenle yükseköğretim kurumlarının ders içerikleri ve müfredatları, muhasebe eğitim amaçlarına uygun şekilde belirlenmelidir (Cheng, 2019, s. 469).

Yükseköğretim lisans ya da lisansüstü eğitimleri kapsamında; muhasebe ve denetim, işletme, iktisat, bankacılık vb. sosyal ve iktisadi bilimlerin tamamında muhasebe bilim dalının dersleri bulunmaktadır. Özellikle profesyonel iş piyasasında daha fazla istihdam olanağı olan söz konusu bölümler için, muhasebe eğitimi azami derecede önemlidir. Bu eğitimin kapsamı tabi ki belirli seviyelerde ve belirli yoğunluklarda farkl1lıklar arz edebilir. Bu farklılık gerekli ve önemlidir. 
Çünkü her bir bölümün ihtiyaç duyacağı eğitim modeli, türü ve kapsamı birbirinden farklıdır. Muhasebe eğitimi; işletme kararlarına yararlı bilgilerin saptanması, toplanması, ölçülmesi, işlenmesi, kaydedilmesi, doğruluğunun denetlenmesi ve raporlanarak özetlenmesi sonucunda karar vermede kullanılacak bilgi ve becerinin öğrencilere yansıtılması amacını taşımaktadır (Sayın vd., 2005, s. 101).

Muhasebe de gerek bir bilim dalı gerekse bir işletme fonksiyonu olarak bilgi teknolojilerinden en fazla etkilenen alanlardan birisi olmuştur. Kayıtların tamamının elle tutulduğu, defter ve belgelerin manuel olarak düzenlendiği dönemlerden tüm işlemlerin bilgisayar ortamında yapıldığı aşamalara gelinmiştir (Onat vd., 2017, s. 316). Eğitim kurumları muhasebe eğitimi verirken, işletmelerin muhasebe meslek mensuplarından olan beklentilerini de göz önüne alarak, vermekte oldukları muhasebe eğitiminin hem piyasa koşullarına uygunluğunu sağlamalı ve hem de kalitesini arttırmaya çalışmalıdırlar (Yıldız ve Durak, 2011, s. 38). Bir bilgi sistemi olan muhasebeye işletmelerde kendisinden beklenene bağlı olarak değişen boyutlarda görevler yüklenir. Bir kısım işletmeler muhasebenin vergi matrahını belirlemesi ve borç ve alacakları izlemesini yeterli bulurken, bir kısım işletmeler ise muhasebeden, tüm ilgi gruplarının ihtiyaçlarına cevap verecek bilgilerin üretilmesini ve rapor edilmesini beklemektedir (Çürük ve Doğan, 2001, s 28).

Bilgi teknolojilerindeki ve ekonomideki hızlı gelişim, artan rekabet ve küreselleşme, işletmelerin muhasebe süreçlerini de etkilemiş, karmaşıklaşan işletme faaliyetlerine karşıllk muhasebecilik mesleğinde yapılan işlemlerin de içeriği farklılaşarak önemi artmıştır. Özellikle kurumsal yönetim, denetim ve finansal raporlama gibi alanlarda yaşanan değişimin etkisiyle muhasebede yeni muhasebe uzmanlık alanları olarak adlandırılabilecek çalışma alanları ortaya çıkmıştır (Yıldız ve Akyel, 2018, s. 48). Dolayısıyla mesleğin icra edilmesine yönelik bilgi birikimi için gerekli nitelikler her geçen gün artmaktadır. Artan nitelikleri kazandırarak işletmelerin ihtiyaçlarına cevap vermek mesleki eğitimin rolünü önemli kılmaktadır (Coşkun vd., 2017, s. 332).

Tüm bunlarla birlikte, özellikle 2000'li yılların başından beri bir uluslararası muhasebe standartları setinin oluşturulması çabası halen devam etmektedir. Türkiye'de bu konuda uluslararası düzenlemeleri takip etmekte ve yerel ihtiyaçlara uygun bir muhasebe standartları seti hazırlanması noktasında ilgili kurumlar aracılığıyla çalışmalarına devam etmektedir. İlgili muhasebe icracılarının (belirli şartları taşımak koşuluyla) muhasebe işlemlerinde bu standartlarını uygulaması zorunludur. Bu nedenle bilgi çağının gereksinimlerine kolay adapte edilecek bir muhasebe setinin varlı̆̆ından eğitim öğretim mecrasının haberdar olması ve bu konuda çeşitli güncellemeler yapması kaçınılmazdır.

Bir muhasebe eğitiminde öğrencilere kazandırılması gereken konular aşağıda özetlenmiştir (Kızıl, 2003, s. 10);

- Bilgi sistemlerinin kurulması ve kullanılmas1,

- İletişim kabiliyeti,

- Organizasyonlarda bilgi ve karar alma becerisi,

- Finansal bilgi ve raporlama,

- Muhasebe mesleğinin ahla ki sorumluluğu,

- Sosyal sorumluluk bilinci,

- Kültürel ve entelektüel birikim

\section{Araştırmanın Amacı, Kapsamı ve Yöntemi}

Çalışma kapsamında, Türkiye'de ki yükseköğretim kurumlarında görev yapan ve muhasebe bilim dalının bünyesinde yer alan herhangi bir dersi veren/vermiş öğretim üyelerinin konuya ilişkin görüşleri alınmıştır. Bu aşamada lisans ya da lisansüstü programları arasında bir ayrıma gidilmemiştir. Bu doğrultuda muhasebe eğitim ve öğretim ekosistemi içerisinde ki temel sorunlar tespit edilmeye çalışılmış ve bunların ilgili evrende ki öğretim üyeleri tarafından derecelendirmeleri istenmiştir. Muhasebe eğitimine ilişkin sorunların tespiti için kişisel gözlemler, genel literatür incelemesi ve derinlemesine mülakat yöntemlerinden faydalanılmıştır.

İlgili verilen analizi için ise AHP (Analitik Hiyerarşi Proses) yöntemi tercih edilmiş ve bu sayede ilgili eğitim öğretim sorunları için farklı kriterler bazında sonuçlara ulaşılmıştır. Bununla birlikte, yine çalışma kapsamında tasarlanan kriterlerin kendi içerisinde yapılan derecelendirme matrisleri sonuçları modele tanımlanmıştır. Söz konusu temel iki sonuçlar marifetiyle, bilgi çağında yükseköğretim muhasebe eğitiminde karşılaşılan sorunlara ilişkin nihai sonuçlar elde edilmiştir. Akabinde elde edilen sonuçlara ilişkin 
öneriler sunulmuştur. İlgili sonuçlar ve öneriler doğrultusunda söz konusu muhasebe eğitim öğretim modeline olumlu katkılar sunulacağı düşünülmektedir.

Bu bağlamda muhasebe eğitiminde karşılaşılan temel sorunlar/eksiklikler şu şekilde kategorize edilmiştir;

- Etkin ders programı/müfredat,

- Öğrencilerin İlgisi/ilgisizliği,

- Güncel seçmeli derslerin eksikliği,

- Bölüm derslerinin ağır olması,

- Yeni öğretim metotlarının geliştirilmemesi,

- Eğitimde teknolojinin az kullanılması,

- Yeni ölçme ve değerlendirme metotları,

- Öğretim Kalitesi,

- Derslerin teori ile sinırlı kalması

Bununla birlikte yine mevcut sorunları/eksiklikleri derecelendirirken şu temel kriterler göz önünde tutulmuştur;

- Katma Değer Oluşturma,

- Mesleki, Kültürel ve Sosyal Donanım,

- Sürdürülebilir İstihdam ve Kariyer,

- Analitik Düşünme Kabiliyeti

Söz konusu alternatiflerin ve kriterlerin veri girişlerinin yapıldığı AHP matrisi örneği aşağıda ki şekilde oluşmuştur. Tüm alternatif ve kriter matrislerinin bu çalışmada gösterilmesi çalışmanın kapsamı gereğince mümkün olmamıştır.

Tablo 1. AHP Matrisi Örneği

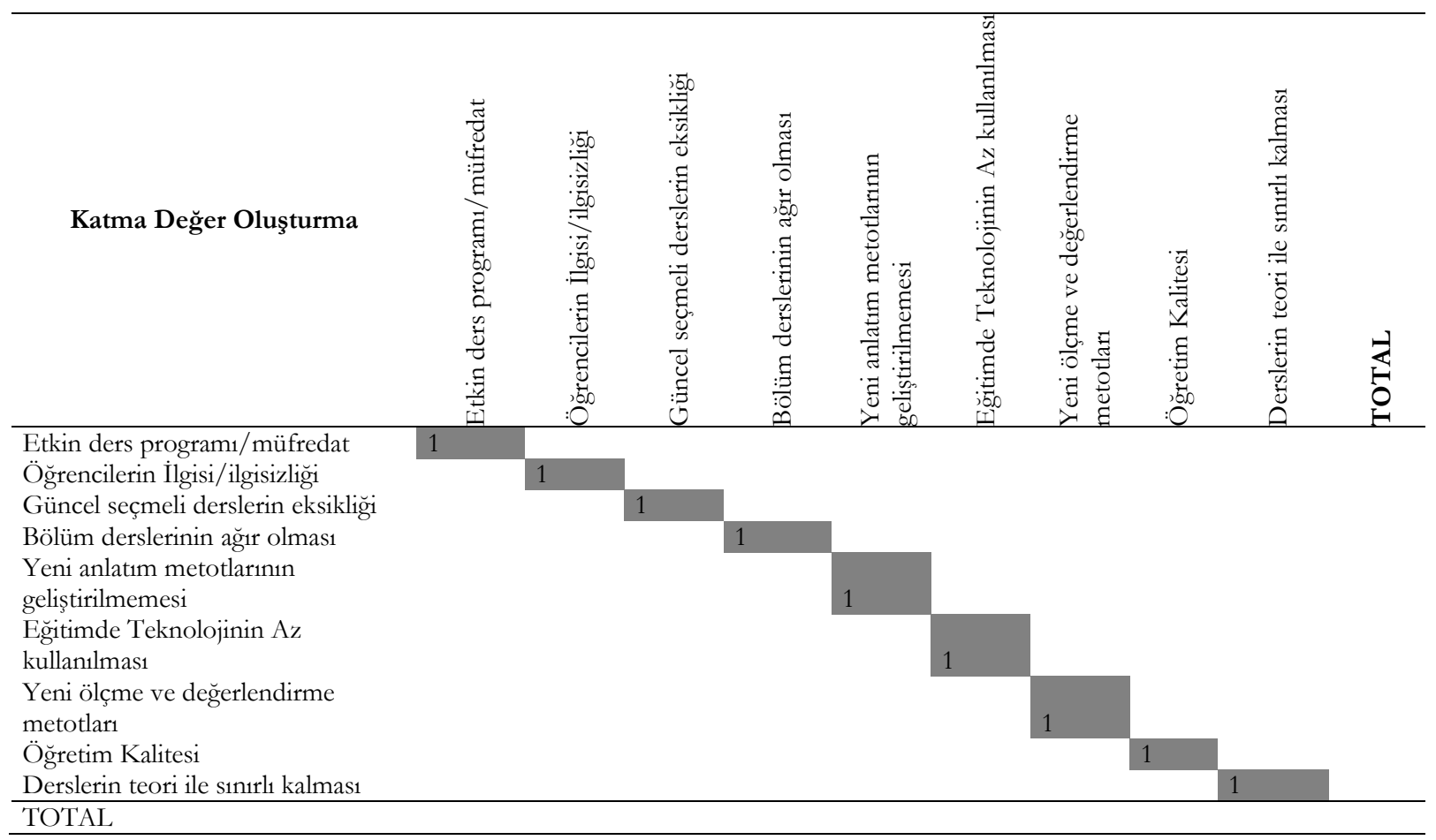




\section{Bulgular}

Çalışma için tasarlanan modele ilişkin sonuçlar şu şekildedir;

\begin{tabular}{|c|c|c|c|c|c|c|}
\hline & $\begin{array}{c}\text { Katma } \\
\text { Değer } \\
\text { Oluşturma }\end{array}$ & $\begin{array}{c}\text { Mesleki, } \\
\text { Kültürel } \\
\text { ve Sosyal } \\
\text { Donanım }\end{array}$ & $\begin{array}{c}\text { Sürdürülebilir } \\
\text { İstihdam ve } \\
\text { Kariyer }\end{array}$ & $\begin{array}{c}\text { Analitik } \\
\text { Düşünme } \\
\text { Kabiliyeti }\end{array}$ & $\begin{array}{l}\text { Geo. } \\
\text { Ort. }\end{array}$ & $\begin{array}{l}\text { Nihai } \\
\text { Yüzde }\end{array}$ \\
\hline Etkin ders programı/müfredat & 0,17 & 0,14 & 0,05 & 0,18 & 0,12 & 0,17 \\
\hline Öğrencilerin İlgisi/ilgisizliği & 0,05 & 0,05 & 0,05 & 0,18 & 0,07 & 0,10 \\
\hline Güncel seçmeli derslerin eksikliği & 0,07 & 0,08 & 0,09 & 0,07 & 0,08 & 0,11 \\
\hline Bölüm derslerinin ağır olması & 0,08 & 0,05 & 0,08 & 0,50 & 0,11 & 0,16 \\
\hline $\begin{array}{l}\text { Yeni öğretim metotlarının } \\
\text { geliştirilmemesi }\end{array}$ & 0,14 & 0,04 & 0,10 & 0,03 & 0,06 & 0,09 \\
\hline Eğitimde Teknolojinin Az kullanılması & 0,02 & 0,11 & 0,09 & 0,04 & 0,05 & 0,08 \\
\hline Yeni ölçme ve değerlendirme metotlar1 & 0,03 & 0,05 & 0,05 & 0,04 & 0,04 & 0,06 \\
\hline Öğretim Kalitesi & 0,13 & 0,10 & 0,07 & 0,10 & 0,10 & 0,14 \\
\hline Derslerin teori ile sınırlı kalması & 0,06 & 0,09 & 0,10 & 0,04 & 0,07 & 0,10 \\
\hline
\end{tabular}

Nihai yüzdeler ve sıralama ise aşağıda ifade edildiği gibi gerçekleşmiştir;

\begin{tabular}{cc}
\hline Yüzde & Nihai Sıralama \\
\hline 0,17 & Etkin ders programı/müfredat \\
0,16 & Bölüm derslerinin ağır olması \\
0,14 & Öğretim Kalitesi \\
0,11 & Güncel seçmeli derslerin eksikliği \\
0,10 & Öğrencilerin İlgisi/ilgisizliği \\
0,10 & Derslerin teori ile sinırlı kalması \\
0,09 & Yeni öğretim metotlarının geliştirilmemesi \\
0,08 & Ĕgitimde Teknolojinin Az kullanılması \\
0,06 & Yeni ölçme ve değerlendirme metotları \\
\hline
\end{tabular}

Nihai derecelendirmeye ilişkin grafik gösterimi ise şu şekildedir;

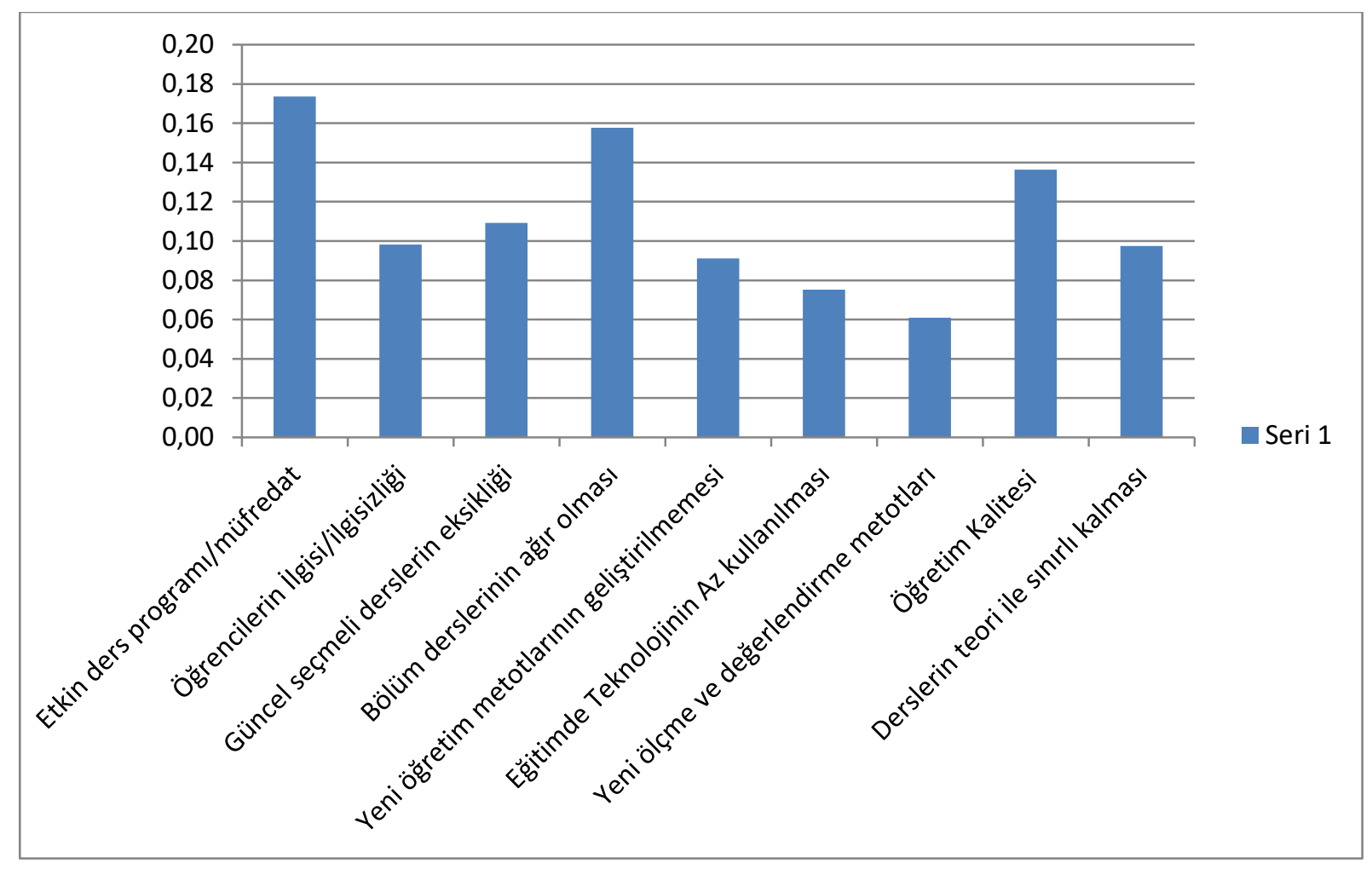




\section{SONUÇ VE ÖNERİLER}

Bilgi çağının beraberinde getirdiği çeșitli ihtiyaçlar hatta zorunluluklar vardır. Bunlar ilgili mecralarında değerlendirildiğinde kalite, kar, zaman vb. çeşitli sonuçlar itibariyle farklılıklara neden olmaktadır. Yani bilgi çağının gereksinimlerini takip eden firmalar karllığını artırabilir, imalat yapan bir birim zaman tasarrufu sağlayabilir ve nihayet bir eğitim kurumu kaliteli çıktılar elde edebilir.

İlgili çalışma kapsamında da belirli yönleriyle değerlendirilmeye çalışlan eğitim konusu, sadece günümüz şartlarını değil geleceğe yönelik çeşitli projeksiyonları da birinci dereceden ilgilendirdiği için önemlidir. Yükseköğretim kurumları açısından ve muhasebe eğitimi kapsamında değerlendirildiğinde, karşımıza çıkan temel sorunlar/engellere ilişkin sonuçlar şu şekilde gerçekleşmiştir;

- Bilgi çağında yükseköğretim muhasebe eğitiminde karşılaşılan en önemli sorun, \%17’lik değerle etkin ders programı/müfredat oluşturulamaması şeklinde tespit edilmiştir. Yükseköğretim kurumlarında müfredatlar ya da ders programları öğrenci ile akademik alış verişin gerçekleştiği en temel araçlarıdır. Müfredat yada ders programınız ne kadar güncel ve ihtiyaca uygun olursa o denli kaliteli ve katma değerli bir muhasebe eğitiminden bahsedebiliyor olunacaktır. Bu nedenle ders programı ve müfredatlar akademisyen endeksli değil, güncel ve katma değerli dersler ile oluşturulmalıdır. Bu sayede yükseköğretim öğrencilerinin ilgi ve dikkatini çekecek programlar ihdas edilebilecektir.

- Bilgi çağında yükseköğretim muhasebe eğitiminde karş̧laşılan en önemli ikinci sorun, \%16’lık değerle bölüm derslerinin ağır olması şeklinde tespit edilmiştir. Söz konusu sonucun en yüksek sorun ile radikal bir farkı bulunmamaktadır. Değerler birbirlerine çok yakındır. Özellikle lisans eğitiminde yer alan temel muhasebe derslerini ilk defa gören (meslek/ticaret meslek liseleri mezun öğrencileri hariç) öğrenciler için bu durum daha net şekilde gözlemlenebilmektedir. Kurallar dizisi şeklinde ilerleyen ve mantıksal kabulleri olan muhasebe biliminin ilk aşamada öğretilmesi büyük zorlukları da beraberinde getirmektedir. Bu noktada ilk etapta muhasebe ile ilgili temel kabuller ve kavramlar detaylı şekilde aktarılmalı, pratikler peşi sıra yapılmalıdır. Maksat çok konu işlemek değil, gerekli olan asgari bilgileri eksiksiz vermek şeklinde tasarlanmalıdır.

- Bilgi çağında yükseköğretim muhasebe eğitiminde karşılaşılan en önemli üçüncü sorun, \%14’lük değerle öğretim kalitesi şeklinde tespit edilmiştir. Bu noktada özellikle öğretici/eğiticinin sınıfın genel durumuna uygun bir seviyede dersi takip edebilmesi büyük önem arz etmektedir. Bununla birlikte akademisyenlerin pedagojik formasyon kurallarına hakim olması gerekmektedir. Dersin işlenişini ve yoğunluğunu yine bu kurallar çerçevesinde şekillendirmesi gerekmektedir. Son olarak derse ilişkin bilgi seviyesi ve düzeyini sürekli güncel tutması ve geliştirmesi gerekmektedir.

- Bilgi çağında yükseköğretim muhasebe eğitiminde karşılaşılan en önemli dördüncü sorun, \%11'lik değerle güncel seçmeli derslerin eksikliği şeklinde tespit edilmiştir. Özellikle farklı konulara ilgisi ve talebi olan öğrenciler bu sayede farklı donanımlar elde edebilir, eğitim-öğretim sürecinde ve sonrasında katma değer oluşturabilirler. Muhasebe mesleğinin en temel sorunlarından birisi katma değer oluşturacak, kaliteli ve donanımlı eleman ihtiyacı olduğu göz önüne alındığında, konunun önemi daha da iyi anlaşılacaktır.

- Bilgi çağında yükseköğretim muhasebe eğitiminde karşılaşılan en önemli beşinci sorun, \%10’luk değerle öğrencilerin İlgisi/ilgisizliği şeklinde tespit edilmiştir. Öğrenci ilgisi ve alakası belirli yönleriyle teşvik edilebilir olsa bile, otonom sorunların başında gelmektedir. Söz konusu sorun, sadece muhasebe eğitiminde değil tüm safhalarda derinlemesine hissedilmektedir.

- Bilgi çağında yükseköğretim muhasebe eğitiminde karşılaşılan en önemli altıncı sorun, \%10’luk değerle derslerin teori ile sınırlı kalması şeklinde tespit edilmiştir. Muhasebe eğitim ve öğretimi teoriler üzerine kurulmuş, pratikler gerekmektedir. Bu nedenle eğitim öğretim döneminde ki teori aktarımına ilişkin seviye çok iyi tespit edilmeli ve ihtiyaç ortaya çıktı̆ı̆nda pratik uygulamalar ile desteklenmelidir. Teorisi aktarılmadan öğretilen pratikler sonucunda, muhasebe mesleğini sadece beyanname veren, vergi konularını takip eden vasat altı eleman çıtasından kurtarmak mümkün olmayacaktır.

- Bilgi çağında yükseköğretim muhasebe eğitiminde karşılaşılan en önemli yedinci sorun, \%9'luk değerle yeni öğretim metotlarının geliştirilmemesi şeklinde tespit edilmiştir. Özellikle bilgi çağının getirmiş olduğu temel avantajlardan birisi de, eğitim-öğretimde yeni metotların kullanılabilmesi olmuştur. Özellikle pratik deneyimin önemli olduğu muhasebe eğitiminde bu konunun ihmal edildiği ve yeni öğretim metotlarının halen geliştirilemediği görülmektedir. 
- Bilgi çağında yükseköğretim muhasebe eğitiminde karşılaşılan en önemli sekizinci sorun, $\% 8$ 'lik değerle yeni öğretim metotlarının geliştirilmemesi şeklinde tespit edilmiştir.

- Son olarak, bilgi çağında yükseköğretim muhasebe eğitiminde karşılaşılan en önemli dokuzuncu sorun, \%6’lık değerle yeni ölçme ve değerlendirme metotlarının eksikliği şeklinde tespit edilmiştir.

\section{Kaynakça}

Alkan, G. (2015). İșletmelerin ön lisans muhasebe eğitiminden beklentileri: İzmir'de bir araştırma. World Of Accounting Science, 17(1), 137-158.

Cheng, Y. (2019, April). Research on the reform of accounting course system guided by accounting education objectives. 1st International Symposium on Education, Culture and Social Sciences (ECSS 2019), Atlantis Press

Coşkun, S., Kir, A. ve Coşkun, S. (2017). İş dünyasının muhasebe eğitiminden beklentilerinin değerlendirilmesine yönelik bir araştırma. Uluslararası Yönetim İktisat ve İşletme Dergisi, 13(5), 330-341.

Çürük, T. ve Doğan, Z. (2001). muhasebe eğitiminin işletmelerin taleplerini karşılama düzeyi: Türkiye örneği. ODTÜ Gelisme Dergisi, 28(3-4), 281-310.

Gökçen, G. (1998). Uygulamacıların muhasebe eğitiminden beklentileri. Marmara Üniversitesi Muhasebe Araștrma Merkezi Mubasebe-Finansman Dergisi, 9, 43-50

Kara, A. (2019). Bilgi çağı Türkiye'sinde üniversite yönetimi. 15 Internatıonal Conference On Knowledge, Economy \& Management Proceedings, Rabat, ss. 11-22

Kızıl, A. (2003). Olması gereken muhasebe eğitimi ve yeni bir yaklaşım. XXII. Türkije Mubasebe Eğitimi Semporyymu, Gazi Üniversitesi İktisadi ve İdari Bilimler Fakilltesi İsletme Bölümü, Antalya, 3-20

Küçükgöksel, N. Ç. ve Akpınar, T. (2016). İstihdam odaklı meslekî eğitime yönelik sorunlar, talep ve beklentiler. Tekirdağ SMMM Odasi, 6, 1-18.

Onat, O. K., Osman, A. K. I. N. ve Aydoğdu, A. (2019). Türkiye'de muhasebe bilgi teknolojileri kullanımının kariyer planlaması etkisi. Mebmet Akif Ersoy Üniversitesi Sosyal Bilimler Enstituisü Dergisi, 9(21), 315-327.

Sayın, Ş., Yeğinboy, Y. ve Tektüfekçi, F. (2005). Dokuz Eylül Üniversitesi İ.İ.B.F.'nde öğrenci açısından ve alt yapı bakımından muhasebe ve finansman eğitiminin etkinliğinin ölçülmesi ve değerlendirilmesi üzerine bir araştırma. Mubasebe ve Finansman Dergisi, 25, 101-108.

Yıldız, F. ve Durak, G. (2011). Üniversitelerde verilen muhasebe eğitiminin kırklareli yöresinde faaliyet gösteren küçük ve orta büyüklükteki işletmelerin beklentilerini karşılama düzeyinin incelenmesi. Mubasebe ve Finansman Dergisi, 49, 37-47.

Yıldız, Ş. ve Akyel, N. (2018). Yeni muhasebe uzmanlık alanlarının muhasebe eğitimindeki yeri ve Türkiye örneği. Mubasebe ve Finansman Dergisi, 79, 47-66.

\section{EXTENDED ABSTRACT}

Higher education develops as a whole with its students, faculty, curriculum and schedule. This integrity is progressing within a unique ecosystem and acquires new components every day. Technological developments, social developments and communal developments lead to different gains or losses. Scientists, managers etc. from different disciplines are brought together in an environment that induces an effective and efficient use of resources. Universities collaborating need to make challenging decisions to adapt rapidly changing circumstances. Specially; education models, students expectations, equipments of academic member are the main topics about this changing. To maximise the use of university resources, many universities have undergone considerable reorganizations. Because this process will break, added values in higher education. Since the higher education ecosystem is exposed to each of these developments separately, change and development emerge as an indispensable consequence. The higher education model, which is designed specifically for the study, does not have any claim in terms of catching the ideal. However, observations, researches and obtained results show that higher education wheels are no longer progressing as powerful as they used to be and they are the precursors of some problems. The expanding framework of the higher education ecosystem should be analyzed with all aspect. This study which examines the basic problems of higher education in accounting education can be applied to each discipline by practicing current components and criteria. This is because the basic higher education ecosystem is not designed on the basis of department, but as a whole administration model. This is the main reason behind this problem of efficient resource allocation in higher education. Problems are becoming more structural in a discipline such as accounting which outweighs the technical sides and claims to gain in practice/profession. The main reason of this can be explained in many ways. The main reasons or alternatives designed for the study are categorized and analyzed on the basis of certain criteria. By this way, the actions to be taken in the short term in accounting education in higher education are determined. These analyzes are examined with multi-criteria decision making processes. In this study, multi-criteria decision making processes were preferred because current problems about higher education for accountings are very complex. The basic assumptions regarding the relevant method are followed. As a result of the matrix analyzes carried out with the expert faculty members, the main problems 
encountered in accounting education in higher education are explained and various suggestions are presented. In this study, especially the main sociological and philosophical problems of higher education are explained. Then, the main threats and opportunities brought about by the information age are presented. In the analysis section, the matrices designed for the faculty members who give accounting education in higher education are analyzed by AHP (Analytic Hierarchy Process) method. AHP is a multicriteria decision-making technique well suited to derive holistic perspectives in this study. AHP's main goal is comparison of alternatives with criterias affects. For this study; criterias are listed as follows;

- Creating Added Value,

- Professional, Cultural and Social Equipment,

- Sustainable Employment and Career,

- Analytical Thinking Ability

The other traditional evaluation techniques are not enough for evaluate and interpert all of this alternatives and criteria. Because the models have quantitative and qualitative aspects for the analysis to be reliable. At this stage, in order to achieve successful and reliable results, it is very important to prefer experts and knowledgeable people. Thanks to the scoring method determined for this method, data is processed into matrices and data sets for analysis are obtained. Analysis of the detected alternatives by considering the relevant criteria started with the creation of matrices. Then, data entries were provided and symmetrical values of each matrix were taken and their consistency was determined. Inconsistent matrices are not included in the model. The same processes were made within each criterion. According to Saaty, who developed this method, the AHP model consists of 4 basic steps (Satty, 204: 9);

- Creating the hierarchy model

- Creating Alternatives Matrices

- Determination of Advantages

- Integration (synthesis)

The relevant faculty members were asked to evaluate the basic problems encountered in accounting education of higher education in multiple criteria and in many alternatives. According to the results, the main reasons are listed as follows;

- Effective schedule/curriculum - \%17

- Department courses are being heavy - \%16

- Quality of Teaching - \%14

- Lack of current elective courses - \%11

- Interest/indifference of students - $\% 10$

- Courses' being limited to theory - \%10

- Failure to develop new teaching methods - \%9

- Less use of technology in education - \%8

- New measurement and evaluation methods - \%6 